\title{
Preferências Domésticas e Instituições do Processo Decisório em Política Econômica Externa*
}

Raphael Coutinho da Cunha

\section{INTRODUÇÃO}

$\mathrm{E}$ ste artigo busca discutir a dinâmica da participação dos atores do¿ mésticos não governamentais no processo decisório de política econômica externa, em especial no tocante às questões comerciais, e sua interação com atores governamentais em diferentes contextos institucionais. Para tanto, são discutidas as respostas que a literatura de ciência política, relações internacionais e economia oferece para as seguintes perguntas: (a) os atores domésticos não governamentais - ou societários - influenciam as decisões de política econômica externa?; (b) o que determina as preferências desses atores por políticas específicas?; (c) que características institucionais do processo decisório oferecem maior ou menor permeabilidade às demandas dos atores domésticos?; (d) como interagem atores governamentais e societários e que variáveis institucionais afetam essa interação?

Como apontam Frieden (2000) e Rodrik (1994), um modelo explicativo da política comercial deve conter quatro elementos básicos. Primeiro, uma explicação sobre as variáveis que influenciam as preferências in-

\footnotetext{
* Este artigo se baseia na dissertação de mestrado do autor, intitulada Preferências Domésticas e Diplomacia Comercial: A Posição Negociadora Brasileira sobre o Comércio de Serviços nas Rodadas Doha e Uruguai, apresentada ao Programa de Pós-Graduação em Relações Internacionais da Universidade de Brasília (UnB) em 2008.
}

DADOS - Revista de Ciências Sociais, Rio de Janeiro, Vol. 52, nº 4, 2009, pp. 871 a 910. 
dividuais em relação às opções de políticas disponíveis. Segundo, uma explicação de como essas preferências individuais são agregadas e canalizadas, por meio das instituições socioeconômicas e políticas, em demandas por determinadas políticas. Terceiro, uma caracterização das preferências dos atores governamentais. Por fim, uma especificação do contexto institucional em que o processo decisório ocorre.

A literatura parte da questão redistributiva do comércio internacional para dela derivar as preferências dos diversos atores domésticos. Dessa forma, os ganhos ou perdas (efetivos e potenciais) com o comércio internacional determinariam as preferências dos atores por políticas de maior abertura ou de maior proteção, ao passo que diferentes grupos de atores teriam propensões distintas a se organizar e demandar suas preferências junto aos tomadores de decisão em política econômica externa. Os modelos teóricos disponíveis buscam estabelecer quais características econômicas dos indivíduos estão associadas a diferentes tipos de preferências. Ademais, processos como a internacionalização da economia e a liberalização negociada com outros países também foram identificados como fatores que interferem nas preferências e nos incentivos à mobilização dos atores domésticos.

Parte da literatura, em especial a referida como abordagem societária, supõe um nexo causal direto entre as preferências dos atores domésticos e os resultados de política econômica externa. No entanto, as características político-institucionais do processo decisório governamental em política econômica externa condicionam a forma pela qual os interesses dos atores domésticos são filtrados e refletidos nas decisões e políticas governamentais. Determinadas características podem aumentar ou reduzir a permeabilidade do processo decisório às demandas societárias e processá-las de formas distintas, acarretando maior ou menor identidade entre preferências domésticas e política externa comercial. No limite, a depender do contexto institucional em que se dê o processo decisório, a política pode ou refletir completamente as preferências dos atores domésticos organizados, ou, pelo contrário, resultar unicamente das preferências autônomas dos atores governamentais.

Como destaca Milner (1997:15), embora seja comum notar que interesses e instituições exercem influência conjunta sobre as políticas públicas, os pesquisadores da área frequentemente favorecem, em suas formulações, uma das variáveis em detrimento da outra. É preciso consi- 
derar, no entanto, que explicações societárias e institucionais devem ser integradas para melhor explicar os resultados de política econômica externa.

Neste artigo, identifico, a partir da literatura, as variáveis mais relevantes para o estudo da influência das preferências societárias sobre as decisões de política econômica externa. Primeiro, discuto os determinantes das preferências de atores societários e governamentais, bem como os fatores que influenciam a propensão dos indivíduos para mobilização e organização em torno da atividade política. Em seguida, trato das limitações de uma abordagem focada exclusivamente em preferências individuais e da necessidade da incorporação de variáveis institucionais às explicações da política econômica externa. Para tanto, são apresentadas três abordagens institucionais principais. Por fim, discuto as limitações que sofrem as explicações centradas em instituições e proponho formas de integração das diferentes explicações parciais.

\section{ATORES E PREFERÊNCIAS}

As teorias que buscam no plano doméstico as fontes da explicação para a política econômica externa nasceram como reação à insatisfação com a abordagem sistêmica da economia política internacional, na qual identificavam pelo menos duas dificuldades fundamentais. Primeiro, restrições sistêmicas permitem um leque limitado de comportamentos; no entanto, os comportamentos observados variam significativamente dentro do escopo desse leque. Segundo, se, por um lado, o sistema internacional recompensa alguns tipos de comportamento e pune outros, isso é igualmente verdadeiro para o nível doméstico. Portanto, os tomadores de decisão precisam compatibilizar ganhos e perdas nos planos externo e doméstico (Milner, 1997; Putnam, 1988; Skidmore e Hudson, 1993).

Além disso, as abordagens que enfatizam os atores domésticos e suas preferências postulam a inevitabilidade do conflito doméstico sobre o que consiste o interesse nacional, de modo que a definição do interesse nacional se torna uma variável central. Atores domésticos possuem preferências distintas e a formação de uma preferência nacional depende dos recursos que os atores detêm e de como as instituições políticas domésticas agregam essas diversas preferências (Milner, 1997:4-5; 1998:772; Moravcsik, 1997:513 e 518; Putnam, 1988:460). 
Uma teoria da política externa, assim, deve mostrar como diferentes fatores domésticos alteram o comportamento externo de diferentes Estados ou de um mesmo Estado ao longo do tempo. As propostas de explicação discutidas nesta seção enfatizam, de um lado, as preferências dos diversos atores que influenciam o processo político doméstico e, de outro, as instituições políticas que condicionam sua forma de atuação.

Deve-se, portanto, identificar, antes de tudo, os atores que podem tomar parte do processo decisório em política econômica externa. A literatura trata de uma série de atores, muitas vezes em diferentes níveis de agregação; divido os atores domésticos em atores governamentais e não governamentais (ou societários). Entre os governamentais estão os poderes Executivo e Legislativo, líderes políticos eleitos que ocupam postos de comando nesses dois poderes e indivíduos pertencentes às carreiras da burocracia que ocupam cargos no alto escalão dos órgãos e das agências governamentais. Entre os atores societários encontramos indivíduos fora do aparato governamental que assumem papéis os mais variados, como consumidores, trabalhadores, empresários, proprietários de terra, líderes sindicais ou de movimentos sociais e representantes das mais diversas associações civis. Em geral, os atores societários adquirem importância à medida que se organizam em grupos, seja qual for sua forma institucional (Moravcsik, 1997:517)1․

Dado o foco nas preferências dos atores domésticos, é necessário definir e diferenciar os conceitos de interesses e de preferências. Os interesses dos atores são seus objetivos fundamentais; os interesses de atores econômicos, por exemplo, envolvem a maximização da renda, enquanto os dos atores políticos envolvem, em grande medida, a maximização das chances de continuar no poder. Já as preferências se referem a opções específicas de políticas que, na visão dos atores, maximizarão sua renda ou suas chances de se manter no poder. Em suma, interesses são a fundação sobre a qual se baseiam as preferências dos atores. Preferências são utilizadas como variável explicativa; interesses, não (Frieden, 2000:37; Milner, 1997:15 e 33).

Para facilitar a instrumentalização das preferências em modelos teóricos, Milner (1997) propõe o conceito de estrutura de preferências domésticas como uma forma sintética de discutir as preferências dos diversos atores. Essa estrutura se refere às "posições relativas" das prefe- 
rências de atores domésticos relevantes no tocante a cada questão específica de política econômica externa (ibidem:16).

Vamos começar discutindo os modelos que tentam explicar a origem das preferências dos indivíduos, sobretudo em questões de política comercial. Em seguida, examino os modelos políticos que buscam compreender como ocorre a transformação das preferências individuais em demandas políticas organizadas. Passo, então, aos efeitos do contexto institucional internacional e da internacionalização econômica sobre as preferências domésticas. Adiante, discuto as explicações existentes sobre a origem das preferências dos atores governamentais; por fim, indico algumas limitações que sofrem os modelos teóricos centrados em preferências domésticas.

\section{Preferências de Indivíduos e Grupos de Interesse (Atores Societários)}

Existem explicações concorrentes sobre a origem das preferências dos atores domésticos societários por determinado tipo de política comercial, as quais se baseiam, principalmente, em dois modelos teóricos do comércio internacional: o modelo Heckscher-Ohlin (ou modelo fatorial) e o modelo Ricardo-Viner (ou modelo setorial). Em ambos os modelos, as preferências dos atores são deduzidas das mudanças em sua renda advindas de mudanças na política comercial (Frieden, 2000:37) e são enfatizados os efeitos redistributivos da política comercial, associando-se preferência por proteção àqueles grupos que perdem com os fluxos comerciais e preferência por liberalização àqueles que ganham. Adota-se a premissa de que os atores maximizam sua utilidade e fazem cálculos de custo-benefício sobre a melhor forma de alcançar seus objetivos (idem, ibidem). Atores preferem, portanto, políticas públicas que maximizem sua renda (ibidem:39). Em suma, o impacto redistributivo de mudanças na política comercial determinará as preferências dos grupos de interesse (Milner, 1997:60).

A abordagem fatorial se baseia no teorema de Stolper-Samuelson do modelo Heckscher-Ohlin, o qual demonstra que, quando há mobilidade dos fatores de produção (como trabalho e capital) entre os setores da economia, o aumento no nível de proteção da economia aumenta a remuneração dos fatores relativamente escassos no país e diminui a dos fatores relativamente abundantes. Os detentores de fatores abundantes, portanto, terão incentivos para tentar liberalizar o comércio, e os detentores de recursos escassos, para restringi-lo (Alt et alii, 1996:692; 
Frieden e Rogowski, 1996:38-39; Krugman e Obstfeld, 2001; Milner, 2002; Milner e Keohane, 1996:8; Scheve e Slaughter, 2001:272-273). O modelo prevê que as clivagens em torno das questões de política comercial vão se formar com base na dotação relativa de fatores produtivos - trabalho versus capital, terra versus capital, trabalho e capital versus terra etc. -, sendo que as linhas de clivagem específicas vão depender da dotação relativa de fatores de cada país (Alt et alii, 1996:692; Baldwin, 1989:120; Rogowski,1987; Milner, 2002:450).

A abordagem setorial, por sua vez, baseia-se no modelo Ricardo-Viner do comércio internacional (também conhecido como teoria dos fatores específicos), segundo o qual vários fatores produtivos são de uso muito específico, de modo que se observam frequentemente efeitos setoriais (e não fatoriais) sobre o comportamento político dos atores. Dado que pelo menos um fator de produção é imóvel (isto é, específico ao setor), todos os fatores ligados a setores que competem com importações perdem com a liberalização comercial, enquanto aqueles empregados em setores exportadores ganham. As clivagens em torno das questões de política comercial, portanto, oporão trabalho, terra e capital em setores ameaçados por importações a trabalho, terra e capital empregados em setores de exportação; serão clivagens setoriais, e não fatoriais (Alt et alii, 1996:692; Frieden e Rogowski, 1996:38; Milner, 2002:451; Scheve e Slaughter, 2001:272-273).

A principal diferença entre os dois modelos está no grau de especificidade dos fatores produtivos ou, inversamente, em seu grau de mobilidade entre os setores da economia - isto é, a facilidade com que podem ser empregados em usos alternativos (Alt et alii, 1996:690; Frieden, 2000:39; Milner, 2002:451; Scheve e Slaughter, 2001:268). Diferentes graus de mobilidade implicam efeitos diferentes sobre a remuneração dos fatores advindos da liberalização comercial; logo, implicam também preferências diferentes por parte dos atores domésticos (Alt et alii, 1999:101-103; Scheve e Slaughter, 2001:272).

Alt et alii (1996:697) argumentam que as premissas diferentes adotadas pelos dois modelos a respeito da especificidade dos fatores são, na verdade, os extremos de um continuum que vai desde a mobilidade sem quaisquer custos até a mobilidade com custos proibitivos. Além disso, alguns economistas tendem a interpretar o modelo de fatores específicos (Ricardo-Viner) como uma versão de curto prazo no modelo de Heckscher-Ohlin (que estaria mais apto a estimar o comportamento de 
longo prazo dos fatores produtivos). Segundo essa interpretação, no longo prazo não há fator que seja completamente específico, enquanto no curto prazo poucos fatores podem ser transferidos entre setores da economia sem custos significativos (Scheve e Slaughter, 2001:272). Assim, análises que utilizam as premissas do modelo Heckscher-Ohlin tendem a gerar melhores previsões quando aplicadas a longos períodos históricos, ao passo que o modelo de fatores específicos é mais apropriado para explicações de períodos curtos. Se os indivíduos avaliarem, na prática, tanto os efeitos de curto quanto de longo prazo, suas preferências comerciais podem depender não apenas do tipo de fator que detêm como também do setor em que estão empregados (Alt et alii, 1996:698; Scheve e Slaughter, 2001:272).

Há, ademais, outra interpretação acerca da especificidade dos fatores. Alt et alii (1999:102) argumentam que as economias podem ser compostas de fatores produtivos cuja especificidade varia de empresa para empresa ou de setor para setor em um dado momento (e não intertemporalmente, como na interpretação exposta anteriormente). O trabalho poderia ser específico a alguns setores, mas não a outros, bem como a terra e o capital, de modo que a política comercial pode não afetar tipos amplos de fatores da mesma forma. Além disso, pode-se admitir maiores variações nos padrões de formação de coalizões; por exemplo, trabalho e capital podem ser aliados em alguns contextos, mas rivais em outros. Nessa perspectiva, empresas com ativos menos móveis - ou mais específicos - são mais propensas a demandar proteção do que empresas com ativos mais móveis - ou menos específicos (ibidem:103). Apesar de ganhar em complexidade e fidelidade à realidade, a abordagem peca por maior indeterminação e perda de capacidade preditiva, visto que requer especificação empírica de suas premissas.

Grande parte dos fluxos de comércio mundial atual, porém, não pode ser explicada pelos dois modelos anteriores (fatorial e setorial). Nenhum dos dois prevê a importância crescente do comércio intraindustrial entre países com dotações relativas de fatores semelhantes (Alt et alii, 1996:693). Uma terceira abordagem, por sua vez, enfatiza a existência de economias de escala em determinadas empresas ou setores econômicos e baseia-se na teoria do comércio intraindustrial, o qual tende a gerar efeitos distributivos diferentes daqueles previstos pelos modelos Heckscher-Ohlin e Ricardo-Viner. Em geral, o comércio intraindustrial é associado a efeitos redistributivos mais amenos e, por conseguinte, a menos conflitos políticos domésticos, pois produz menores 
custos de ajuste (idem, ibidem:694; Krugman, 1983; Milner, 2002:450; Rodrik, 1994:6).

Como argumentam Alt et alii (1996), o modelo de comércio intraindustrial pode gerar consequências distributivas neutras e a possibilidade teórica de que todos ganhem com o aumento dos fluxos comerciais. Essa última consequência ocorre porque, com a diferenciação de produtos, o aumento do comércio não causa o fechamento ou a redução de nenhuma linha de produto, uma vez que nenhum produto idêntico é produzido por outra empresa, e nenhum proprietário de determinado fator produtivo perde com a realocação setorial (ibidem:694). Em termos de formação de coalizões, em setores caracterizados por economias de escala, a abertura da economia aumenta as vantagens das empresas grandes em relação às pequenas. Nesse caso, a demanda por liberalização varia, essencialmente, de acordo com o tamanho da empresa e a intensidade das economias de escala (Frieden e Rogowski, 1996:39-40; Milner e Yoffie, 1989). Os conflitos políticos, portanto, são menos intensos nos casos em que o comércio intraindustrial predomina sobre o interindustrial, baseado em vantagens comparativas.

Outros estudos buscam explicar as origens das preferências com base em características particulares de setores específicos da economia. Alguns argumentos associam as preferências de setores específicos com seu grau de internacionalização, de forma que setores exportadores e empresas multinacionais tenderiam a favorecer a liberalização comercial e a receber menos proteção do que aqueles voltados para o mercado interno (Milner, 1997:63; 2002:451; Milner e Keohane, 1996:8). Logo, segundo essa perspectiva, as preferências dos grupos societários e as clivagens políticas entre eles dependem de seu grau de exposição à economia internacional.

Alguns estudos realizaram testes empíricos dos modelos que buscam explicar a formação das preferências comerciais dos indivíduos e dos grupos domésticos. Rogowski (1987) conclui, a partir da análise de alguns períodos históricos de expansão e de contração dos fluxos comerciais, que o aumento do comércio internacional tende a gerar clivagens urbano-rurais em alguns contextos e conflitos de classe em outros. Isto é, as clivagens em torno das questões de política comercial tendem a gerar conflitos entre trabalhadores, capitalistas e proprietários de terra, dando suporte ao modelo fatorial (Heckscher-Ohlin). A depender da dotação relativa de fatores do país, coalizões podem opor trabalha- 
dores e capitalistas a proprietários de terra (conflito urbano-rural) ou, em outros casos, capitalistas e proprietários de terra a trabalhadores (conflito de classe).

Scheve e Slaughter (2001:288) concluem, com base em testes estatísticos, que existe alto grau de mobilidade intersetorial dos fatores no horizonte temporal relevante para os indivíduos na avaliação de políticas comerciais. Seus resultados são mais consistentes com o modelo Heckscher-Ohlin do que com o modelo Ricardo-Viner, indicando que a dotação de fatores é determinante na explicação da formação das preferências. Sua análise estatística sugere, ademais, que a posse de imóvel também interfere na determinação das preferências individuais em relação ao comércio; além da remuneração dos fatores produtivos, as preferências dependem dos ativos não produtivos (como imóveis) que os indivíduos possuem e dos efeitos do comércio internacional sobre o valor desses ativos (ibidem:270-271). Rodrik e Mayda (2001), por sua vez, concluem que preferências por liberalização possuem grau significativo de correlação estatística com o nível de capital humano do indivíduo, da forma prevista pelo modelo fatorial (Heckscher-Ohlin). Preferências em relação ao comércio também apresentam alguma correlação, embora menos significativa, com a exposição ao comércio do setor em que o indivíduo está empregado: indivíduos em setores de bens não comercializáveis tendem a ser mais favoráveis à liberalização, enquanto aqueles empregados em setores com desvantagem comparativa são mais protecionistas.

Por outro lado, Frieden (2000:39) e Hathaway (1998:580) argumentam que as indústrias caracterizadas por habilidades, maquinário e redes de fornecimento e distribuição específicos serão mais motivadas a influenciar as políticas em seu favor. Alt et alii (1999) oferecem evidência empírica para esse argumento. Sob pressão de concorrência internacional, empresas cujos ativos sejam mais específicos (ou menos móveis) são mais propensas a demandar proteção ao governo. Assim, variações na especificidade dos fatores de empresa para empresa ou de setor para setor são importantes para explicar o comportamento político de indivíduos e grupos.

Não há conclusões definitivas sobre qual modelo explicativo produz melhores resultados quando confrontado com as evidências. Como discutido, o horizonte temporal da análise pode determinar qual modelo é mais apropriado. Dependendo da área temática e das conse- 
quências redistributivas, explicações baseadas em fatores produtivos podem ser mais bem-sucedidas; em outros casos, setores e empresas específicos podem ser mais apropriados (Milner, 1997:63). Ademais, a flexibilização das premissas de cada um pode contribuir para melhores resultados explicativos em casos específicos, em detrimento do rigor e da parcimônia.

Finalmente, as explicações sobre a demanda por política comercial precisam ser integradas com explicações sobre os determinantes da ação política. Como aponta Rodrik (1994:2), o modelo deve conter uma explicação de como as preferências individuais são agregadas e canalizadas em demandas por determinadas políticas. A maioria dos modelos trata esse componente implicitamente; alguns, entretanto, buscaram explicitá-lo em modelos de ação coletiva.

\section{Mobilização para a Atividade Política}

Os modelos econômicos apresentados especificam as preferências societárias em relação à política comercial, mas nenhum deles explica como suas implicações redistributivas são expressas na arena política, nem qual é o resultado em termos da composição de coalizões. Não é possível deduzir a formação e a composição das coalizões apenas com base na especificação das preferências. Não é suficiente que os atores tenham incentivos para tentar influenciar as políticas; eles precisam se organizar para exercer pressão política efetiva (Alt et alii, 1996:695; Frieden, 2000:40).

Existe um conjunto de modelos políticos baseados em custos de ação coletiva, os quais tentam explicar como as preferências dos atores se traduzem em coalizões políticas, isto é, em ação política efetiva (Alt et alii, 1996:690). Uma ferramenta para explicar que tipos de grupos serão formados é a lógica da ação coletiva (Olson, 1977). Ao decidir sobre a realização de ação política, indivíduos fazem cálculos de custo-benefício; o lado da equação relativo aos benefícios pode ser entendido por meio dos modelos de preferências já apresentados, em que a intensidade dos benefícios esperados pelos indivíduos varia de acordo com variáveis como a dotação relativa dos fatores, seu grau de especificidade, entre outras. Por outro lado, os indivíduos levam em conta os custos da ação coletiva, e esses custos podem ser potencializados pelo problema do carona (idem, ibidem). A formação e a coesão das coalizões dependerão, portanto, de como os indivíduos percebem a intensidade de suas 
preferências e os custos associados à ação política. A literatura sobre ação coletiva sugere ainda que a coesão dos grupos depende de fatores tais como o tamanho do grupo e sua capacidade de fornecer benefícios seletivos para seus membros (Frieden, 2000:40). Em geral, grupos pequenos com interesses específicos se organizam mais facilmente e garantem benefícios mais efetivamente do que grupos grandes com interesses difusos.

Os primeiros modelos políticos de ação coletiva trataram de clivagens entre produtores e consumidores. As primeiras conclusões teóricas no campo da economia política da proteção refletiram os insights de Downs (1999) e Olson (1977), segundo os quais os interesses dos produtores prevaleceriam sobre os dos consumidores nas decisões dos formuladores de políticas (Baldwin, 1989:121). Isso decorre do fato de que cada grupo - consumidores e produtores - enfrenta custos diferentes de mobilização, organização e atuação política. Um grupo de produtores de determinado setor da economia tende a ser composto de um número pequeno de indivíduos, e os possíveis ganhos de uma política de proteção ou perdas de uma política de abertura tendem a ser significativos para cada membro do grupo. Os produtores, portanto, terão grande incentivo para arcar com os custos de informação, mobilização e organização, com vistas a exercer pressão organizada sobre os agentes públicos, em busca de políticas que lhes sejam favoráveis. Por outro lado, o grupo dos consumidores é difuso e composto de um número enorme de indivíduos. Os possíveis ganhos ou perdas, ainda que altos em termos absolutos, serão ínfimos em termos per capita, e, por isso, nenhum indivíduo do grupo terá incentivo suficiente para incorrer em custos de informação e organização na busca por políticas que lhe sejam benéficas. Grosso modo, portanto, Downs (1999) e Olson (1977) indicam que produtores de determinados setores se organizarão de forma mais efetiva do que os consumidores e conseguirão garantir para si proteção comercial. Ademais, subjaz a essa literatura a noção de um mercado político de proteção, em que setores demandantes oferecem votos e contribuições de campanha a políticos que retribuem em forma de proteção comercial. Nesse caso, o governo é visto como um conjunto de indivíduos autointeressados que atuam no mercado político (Caporaso e Levine, 1992:126-143; Odell, 1990:142).

Com base nas conclusões desse modelo político, esperar-se-ia que os governos sempre oferecessem proteção completa aos setores econômicos prejudicados por importações, e não se conseguiria explicar, dessa 
forma, as políticas de abertura de mercado. De fato, o modelo prevê uma tendência à perpetuação de políticas de proteção (Milner, 2002:449; Rodrik, 1994:26), mas faltam a ele considerações sobre as dinâmicas políticas relativas aos setores competitivos da economia. Como, de acordo com o modelo, não se pode esperar que consumidores se organizem para demandar liberalização, deve-se incluir, nas explicações da política econômica externa, as dinâmicas de ação coletiva dos grupos de produtores interessados na liberalização (aqueles próximos à vantagem comparativa do país). Para suprir essas dificuldades, alguns autores incluíram, em sua análise, os efeitos do contexto institucional internacional sobre as dinâmicas políticas domésticas; para isso, introduziram considerações sobre as dinâmicas dos jogos de dois níveis e trataram de demonstrar alguns dos incentivos à ação coletiva para os grupos de produtores não protecionistas.

\section{Contexto Institucional Internacional}

As instituições internacionais são aqui consideradas não por seu papel na agregação de preferências no âmbito do sistema internacional, mas pelas oportunidades e restrições que apresentam aos atores domésticos. Isto é, as instituições internacionais interferem nos incentivos à ação coletiva dos diferentes atores societários domésticos e, por isso, podem ser consideradas variáveis intervenientes na explicação dos resultados da política econômica externa dos países.

Alguns estudiosos introduziram a análise dos jogos de dois níveis proposta por Putnam (1988) nos modelos explicativos da política comercial, o que permitiu a explicação de situações em que as negociações internacionais afetavam o processo político doméstico e vice-versa (Cortell e Davis Jr., 1996; Davis, 2003; 2004; Goldstein e Martin, 2000). De forma geral, a introdução dessa dinâmica buscou explicar como instituições internacionais promovem a liberalização comercial na presença de forte pressão de grupos domésticos (Davis, 2003:2). O objetivo é explicar como o contexto institucional da negociação comercial pode ajudar a contornar demandas bem organizadas de determinados grupos e tornar politicamente possível a liberalização. O foco, portanto, é sobre a liberalização negociada (idem, ibidem:3).

Enfatizam-se as instituições específicas às negociações comerciais, isto é, a agenda, as regras e os procedimentos que regulam a interação entre os países (ibidem:22; Davis, 2004:153). A explicação passa, essencial- 
mente, pela existência de issue linkages em determinadas negociações internacionais, quando a estrutura da negociação condiciona a liberalização de determinado setor (como o agrícola) à abertura de outro setor (como serviços ou bens industrializados). Na presença dessa condicionalidade, grupos potencialmente beneficiários do livre-comércio têm maior incentivo a se mobilizar para pressionar pela abertura do mercado de seu país. Grupos de exportadores passam a demandar abertura ao governo, na medida em que a abertura do mercado doméstico passa a ser necessária para a obtenção de ganhos de acesso aos mercados estrangeiros. O processo de issue linkage, portanto, deve engajar setores que favoreçam a liberalização no debate político para contrabalançar os setores que preferem proteção (idem, 2003:42; 2004:157). Negociações com issue linkages diluem a influência de setores protecionistas porque os forçam a competir com outros grupos de interesse na arena política (Davis, 2003:45)².

Os governos, por sua vez, aceitando um compromisso de liberalização, incorrem em menores custos políticos do que os que enfrentariam no caso de abertura unilateral (Lusztig, 2004). Nesse caso, o processo negociador acaba por ajudar a compensar os problemas de ação coletiva domésticos que resultam em políticas de proteção. Como afirma Davis (2004:167), isso evidencia a possibilidade de que a estrutura de uma negociação internacional contrabalanceie o mercado político da proteção comercial na arena doméstica. Em suma, a estrutura da negociação internacional - em torno de issue linkages - altera o equilíbrio doméstico de interesses a favor da liberalização (Davis, 2003:15; 2004:154).

Por sua vez, Goldstein e Martin (2000) enfatizam o papel das instituições internacionais no fornecimento de mais e melhores informações sobre as implicações redistributivas domésticas dos acordos comerciais de liberalização. A partir disso, extraem conclusões diferentes sobre os efeitos do contexto institucional internacional sobre a política doméstica. Informações sobre quem ganha e quem perde afetam os incentivos para a mobilização dos grupos (ibidem:603-604). À diferença de Davis, no entanto, essa abordagem gera previsões ambíguas a respeito dos efeitos das instituições internacionais sobre o processo de liberalização, sobretudo no que tange à dinâmica política doméstica. Seu objetivo é alertar sobre as dificuldades potenciais que a legalização internacional pode gerar para o processo multilateral de liberalização (ibidem:605). 
Uma das consequências do provimento de informações por parte de instituições internacionais é a maior transparência e previsibilidade sobre os efeitos distributivos da liberalização. O aumento da quantidade e da qualidade dessas informações, porém, gera efeitos dúbios sobre a mobilização de interesses domésticos e, portanto, sobre a capacidade dos governos de manter o apoio a políticas de liberalização, de forma que os efeitos sobre a dinâmica política dependem do equilíbrio vigente entre interesses exportadores e protecionistas (ibidem). No caso em que os interesses exportadores já são bem organizados, mais conhecimento sobre as consequências redistributivas aumenta a mobilização relativa de forças protecionistas; nesse sentido, mais transparência pode tornar as negociações para liberalização politicamente mais difíceis. Embora as informações sejam igualmente importantes para protecionistas e defensores do livre-comércio, "se esses grupos estiverem mobilizados em graus distintos previamente ao processo de legalização, a disseminação de informação terá um efeito marginal maior sobre os grupos que estiverem menos organizados" (ibidem:606; tradução do autor).

Em resumo, os argumentos teóricos oferecem resultados ambíguos acerca dos efeitos do contexto institucional internacional sobre a política dos grupos societários. Eles apontam direções para a pesquisa, mas as respostas têm de ser buscadas na análise empírica e na melhor especificação dos modelos.

\section{Efeitos da Internacionalização Econômica sobre a Estrutura de Preferências Domésticas}

Os fluxos de comércio internacional também podem afetar a política doméstica dos países e, por conseguinte, suas políticas comerciais. Nesse caso, o aumento do comércio internacional - também chamado de internacionalização da economia - é estudado como variável independente na explicação da política comercial; o aumento dos fluxos de comércio produziria mudanças importantes nas preferências, instituições e política domésticas (Milner, 2002:449). O ponto em comum entre os diferentes argumentos sobre a internacionalização é a sugestão de que o aumento da exposição da economia nacional ao livre-comércio leva ao aumento de pressões contra a proteção e, assim, cria um ciclo virtuoso de demandas crescentes por liberalização (idem, ibidem:456). Milner (1999), Milner e Keohane (1996), Frieden e Rogowski (1996) e Rogowski (1987) propõem uma abordagem estática, enquanto 
Hathaway (1998) e Lusztig (2004) trabalham explicações dinâmicas dos efeitos da internacionalização econômica sobre a política doméstica.

Modelo estático - Rogowski (1987) argumenta que, à medida que os países abrem sua economia, o setor de bens comercializáveis tende a crescer juntamente com a exposição às pressões econômicas externas; isso leva a novas clivagens políticas e a conflitos entre fatores escassos e abundantes. Milner (1988) também argumenta que o aumento da abertura econômica muda as preferências domésticas, elevando o número potencial de defensores do livre-comércio, uma vez que cresce o número de empresas exportadoras e multinacionais. Por outro lado, a abertura também pode causar a diminuição do número de empresas protecionistas na medida em que elas sucumbam à concorrência estrangeira.

Frieden e Rogowski (1996:31) argumentam que a facilitação do comércio internacional aumenta a transmissão das tendências econômicas mundiais para as economias nacionais. Dessa forma, ela torna mais intensas as preferências dos atores em relação à política econômica externa dos governos. Ademais, a internacionalização afeta as preferências dos atores domésticos de forma previsível, com base em seus interesses econômicos. Os produtores mais próximos à vantagem comparativa do país tendem a favorecer políticas de maior abertura, enquanto os produtores prejudicados tendem a se opor. Logo, como ganhadores e perdedores têm interesses conflitantes, novas coalizões que se baseiam nos diferentes efeitos da maior abertura econômica serão formadas (ibidem:29 e 37; Milner e Keohane, 1996:15).

No entanto, mudanças de preferências não dizem muito sobre como as políticas e as instituições mudarão em decorrência da internacionalização: é preciso saber também qual será seu efeito sobre a influência política relativa dos diversos atores (Milner e Keohane, 1996:15). Rogowski (1987:1123) afirma que aqueles que sofrem um aumento repentino no nível de renda terão maior capacidade de expandir sua influência política. Essencialmente, o modelo estático postula que várias condições exógenas criam novos atores com preferência pela liberalização, o que altera o equilíbrio de poder a seu favor (Milner, 1999:97).

Modelo dinâmico - Hathaway (1998) e Lusztig (2004) propõem modelos de preferências societárias dinâmicas para explicar variações nas demandas por proteção ao longo do tempo. Como reação ao aumento da 
concorrência externa no mercado doméstico, as empresas domésticas devem optar entre duas formas possíveis de ação: ajuste ou ação política. O primeiro caminho - ajuste - envolve uma série de mudanças, na estrutura da empresa, destinadas à adequação às novas condições de mercado. O caminho alternativo é a ação política, isto é, o ato de reclamar ou de se organizar para reclamar, com a intenção de recuperar as vantagens perdidas com a liberalização (Hathaway, 1998:578). Os diferentes setores podem adotar um dos dois caminhos (ajuste ou mobilização) ou combinações dos dois. À medida que as empresas de um setor realizam ajustes em resposta ao aumento da concorrência internacional, o agregado de preferências do setor econômico muda, já que o ajuste bem-sucedido reduz a severidade de futuros ajustes e, portanto, os potenciais custos de futuras liberalizações (idem, ibidem:577).

As empresas que sobrevivem a processos de liberalização podem até mesmo se tornar competitivas no mercado internacional (ibidem:585). Como consequência, essas empresas se tornam menos propensas a demandar proteção e, eventualmente, podem se tornar demandantes de mais liberalização. Ademais, as empresas menos eficientes do setor que forem incapazes de realizar ajustes terminam por deixar o mercado. O setor fica, portanto, mais propenso a favorecer - ou, ao menos, menos propenso a se opor a - futuras liberalizações (ibidem:585-586). Portanto, no modelo de Hathaway, a liberalização comercial tende a reduzir, ao invés de aumentar, a demanda por proteção por parte daquele setor (ibidem:576).

Por sua vez, Lusztig (2004) argumenta que, sob determinadas condições, oponentes da liberalização podem acabar se tornando aliados importantes de governos na implementação de reformas comerciais. Esse autor estabelece uma tipologia para diferenciar os diferentes grupos protecionistas em termos de sua capacidade (e disposição) de realizar ajuste. De um lado estão os grupos inflexíveis (inflexible rent-seekers), que consistem de produtores domésticos cujo capital é imóvel e que investiram em setores que não conseguem competir no mercado internacional. Esses produtores tendem a investir consideravelmente em atividade política (Lusztig, 2004:7). De outro lado estão os grupos flexíveis (flexible rent-seekers), que também preferem arcar com os custos da atividade política a fazer ajuste, mas que são capazes de, em último caso, reestruturar suas operações para se tornarem competitivos no mercado internacional. Analogamente à explicação de Hathaway (1998), na medida em que os grupos flexíveis se ajustam às novas con- 
dições de concorrência impostas, têm menos incentivos para demandar proteção (ibidem:8).

Ambos os argumentos sugerem, portanto, que o próprio processo de liberalização e de abertura da economia pode gerar mudanças de preferências entre os atores societários domésticos e criar grupos com preferência pela abertura que, por sua vez, apoiarão - ou, ao menos, não mais resistirão a - tentativas subsequentes de liberalização.

É apropriado fazer uma distinção conceitual entre as explicações estáticas e dinâmicas relativas aos efeitos da internacionalização. Nos modelos estáticos, o aumento nos fluxos comerciais de um dado país altera a estrutura doméstica de preferências ao gerar incentivos para que atores que antes não participavam do processo político se mobilizem e passem a demandar suas preferências junto aos decisores públicos. A internacionalização, portanto, não altera as preferências de cada ator específico, mas a configuração de preferências no agregado, uma vez que os atores que participam do jogo político mudam. Em outras palavras, a explicação mostra que, por exemplo, se mais atores com interesse na liberalização entram na disputa política, a estrutura doméstica de preferências passa a refletir o peso relativamente maior dessas preferências; logo, interesses protecionistas adquirem peso relativamente menor. Deve-se notar que, nesse caso, não houve mudança na preferência de nenhum ator específico, mas no equilíbrio agregado entre preferências diversas. Por outro lado, os modelos dinâmicos argumentam que a internacionalização da economia doméstica pode alterar as preferências de alguns atores ao longo do tempo, visto que estes se ajustam às condições de concorrência externa impostas pela liberalização. Os atores que optam pelo ajuste - e são bem-sucedidos - terão menos interesse em proteção e, portanto, serão menos propensos a demandá-la. Ao mesmo tempo, atores que optam pelo não ajuste (e não conseguem proteção) ou que não têm sucesso no processo de ajuste deixarão o setor, diminuindo o número de demandantes de proteção. Nesse modelo, as mudanças previstas pelo modelo estático ocorrem em paralelo com mudanças nas preferências de atores específicos. Muda, portanto, a estrutura doméstica de preferências, sobretudo porque, com o decorrer do tempo, mudam as preferências de atores importantes.

\section{Preferências dos Atores Governamentais}

Autores diferentes tratam dos atores governamentais em níveis distintos de agregação. Alguns trabalham no nível dos poderes Executivo e 
Legislativo - e os consideram unitários e racionais (Milner, 1997); outros tratam dos atores burocráticos - isto é, ministérios, departamentos, agências governamentais e indivíduos que ocupam cargos importantes nesses órgãos (Allison e Halperin, 1972). Outros ainda lidam com líderes políticos individuais e enfatizam os determinantes cognitivos de seu comportamento (Goldstein e Keohane, 1993; Kemp, 2007). Portanto, a escolha do nível de análise influenciará, em grande medida, a explicação da origem das preferências dos atores governamentais.

Aqueles que estudam os poderes Executivo e Legislativo como atores do processo decisório em política externa e em política comercial os concebem como atores unitários e racionais basicamente por motivos heurísticos - isto é, para fins de investigação e de criação de hipóteses empiricamente testáveis. A maximização da utilidade do Executivo depende da reeleição; isso quer dizer que escolherá políticas que sirvam imediatamente a seus interesses eleitorais (Milner, 1997:34; Van Belle, 1993). No modelo, suas chances de reeleição dependem de dois fatores: o estado geral da economia e as preferências dos grupos de interesse que o apoiam (Milner, 1997:34-35). Embora, em último caso, são os eleitores que definem o destino dos líderes políticos, grupos de interesse podem ser importantes no provimento de contribuições de campanha, votos, exposição na mídia etc. O Poder Legislativo também é considerado unitário e racional. Novamente como recurso metodológico, entende-se por preferências do Legislativo as preferências do legislador médio (idem, ibidem:35). A reeleição dos legisladores também depende do estado geral da economia e do apoio de grupos de interesse, com peso relativamente maior para o último.

Por que, então, se Legislativo e Executivo compartilham interesses comuns, frequentemente diferem em suas preferências por políticas específicas? De acordo com os autores, porque eles representam eleitorados diferentes. O Executivo responde a um eleitorado nacional; por isso, é responsável pelo desempenho agregado da economia, fator esse que lhe constrange mais do que ao Legislativo. Além disso, o Executivo também deve se preocupar com elementos externos ao sistema político nacional, pois suas preferências também são afetadas pelas demandas e pressões de parceiros internacionais. Por outro lado, o Legislativo se preocupa com um eleitorado local; por isso, é mais permeável a interesses particulares e possui preferências que divergem do Executivo (Lima e Santos, 2001:127; Milner, 1997:36; Nielson, 2003:473). 
Executivos e legislativos, porém, não são atores unitários. Na prática, seus conflitos internos podem, algumas vezes, ser mais intensos e complexos do que suas disputas com outros atores (Milner, 1997:34). Deve-se, portanto, considerar a abordagem da política burocrática, que trata exclusivamente das disputas internas entre agências do Poder Executivo. Nessa perspectiva, os atores políticos são as grandes organizações e os indivíduos que ocupam postos no alto escalão dessas organizações e competem na tentativa de influenciar tanto as decisões quanto as ações do governo (Allison e Halperin, 1972:42). Dessa forma, as ações governamentais podem ser entendidas como o resultado de barganhas entre atores hierarquicamente posicionados no governo (idem, ibidem:43). O indivíduo aqui possui importância, uma vez que ocupa uma posição hierárquica na burocracia estatal. Suas percepções e preferências têm origem tanto em suas características individuais quanto em sua posição na estrutura burocrática. Segundo Allison e Halperin (ibidem:48), os interesses que afetam as preferências dos atores podem ser enquadrados em quatro categorias: interesses de segurança nacional; interesses organizacionais; interesses domésticos; e interesses pessoais. Entretanto, o modelo acaba por deixar implícito que a origem das preferências do indivíduo recai completamente sobre sua posição na estrutura burocrática.

O sucesso de cada jogador na disputa política depende basicamente de suas vantagens na barganha (controle sobre informação e sobre instrumentos de implementação de políticas) e de sua habilidade e disposição em utilizar essas vantagens (ibidem:50). Contudo, como apontam Hollis e Smith (1986:276), o modelo burocrático possui um nível elevado de indeterminação em suas explicações; não é capaz de gerar previsões específicas e verificáveis sobre quais atores terão mais chances de sucesso - e sob quais condições. Sobretudo, permanece sem resposta a questão de como funciona o poder nas barganhas interburocráticas e qual é sua origem (ibidem:281; Katzenstein, 1977a:599).

Há que se considerar, ademais, que as preferências dos indivíduos que ocupam cargos políticos eletivos ou cargos burocráticos de alto escalão dependem fortemente de suas convicções político-ideológicas (Lima e Santos, 2001:127). Alguns autores argumentam que, na determinação da política comercial, as preferências e ideias dos tomadores de decisão podem ser mais importantes do que as preferências de grupos societários domésticos. Mudanças em suas ideias sobre política comercial podem ter papel importante na determinação das escolhas de polí- 
ticas específicas. Aqui entram as explicações que privilegiam o papel independente das ideias, valores, crenças e vieses cognitivos na determinação das preferências dos atores e dos conteúdos das políticas. $\mathrm{O}$ que se deve enfatizar, nesse caso, são as inter-relações entre ideias e interesses para a compreensão da política econômica externa (Bhagwati, 1988:xii; Milner, 2002:452; Odell, 1990:149)³.

Goldstein e Keohane (1993) tentam mostrar como ideias ajudam a explicar resultados políticos, particularmente aqueles relacionados à política externa. Esses autores distinguem três tipos de ideia ou crença: visões de mundo, crenças de princípios e crenças causais. Ademais, propõem três mecanismos causais por meio dos quais as ideias podem influenciar políticas: primeiro, podem atuar como mapas cognitivos (road maps) que esclarecem objetivos ou relações entre fins e meios para os decisores; segundo, podem ajudar a definir estratégias em jogos que não possuem equilíbrio único; terceiro, podem se inserir em instituições políticas, de modo que persistam no tempo e continuem influenciando políticas mesmo depois que as condições que lhes deram origem não mais existam (Goldstein, 1988; Goldstein e Keohane, 1993:7-8). As abordagens sobre ideias - por causa da dificuldade de definir, observar e mensurar a variável - padecem também de considerável indeterminação em duas explicações. Como afirma Odell (1990:152), faltam proposições gerais que ajudem a explicar por que algumas ideias se tornam mais influentes do que outras ou quais ideias estão diretamente relacionadas a aspectos específicos da política econômica externa. As abordagens teóricas existentes são imprecisas e se apoiam, sobretudo, em estudos empíricos interpretativos. Faltam propostas de explicação mais rigorosas, capazes de oferecer direções menos incertas às pesquisas da área.

Ainda no campo das explicações cognitivas sobre as preferências comerciais, Kemp (2007) mostra como uma série de vieses cognitivos pode afetar a forma pela qual atores governamentais percebem e respondem a problemas de política comercial. Há alguns fatores principais identificados na literatura da psicologia econômica que podem explicar vieses negativos em relação ao livre-comércio: primeiro, as visões de utilidade dos indivíduos tendem a enfatizar emprego em detrimento de consumo; segundo, há vieses resultantes da aversão ao risco que favorecem o status quo (Baldwin, 1989:123-124); terceiro, indivíduos consideram questões de justiça (fairness) em situações de barganha; quarto, nem todos compreendem plenamente o princípio da van- 
tagem comparativa. É interessante notar que os efeitos desses fatores psicológicos sobre as atitudes dos indivíduos parecem ser cumulativos em vez de independentes (Kemp, 2007:37).

Cabe adicionar que a internacionalização da economia doméstica gera oportunidades e restrições não apenas para os grupos societários, como discutido, mas também para os atores governamentais (Milner e Keohane, 1996:4). Segundo Milner (1997:43-44), dois fatores afetam as preferências dos atores governamentais: o grau de abertura da economia e as externalidades que os países estrangeiros podem impor à economia nacional. A abertura pode implicar perda de eficácia dos instrumentos tradicionais de política econômica, além de significar que os preços relativos do país sofrem restrições e choques do mercado internacional. Essas restrições geram incentivos para a adoção de uma política econômica externa cooperativa, visando à coordenação de políticas nacionais. Por outro lado, políticas de cooperação geram custos, sobretudo aqueles relacionados às consequências distributivas da cooperação e à perda de controle sobre os instrumentos de política econômica. Os atores políticos, portanto, fazem cálculos de custo-benefício que levam em conta os elementos já discutidos (ibidem:46-47; Milner e Keohane, 1996:17).

\section{Limitações das Abordagens Centradas em Preferências}

Os modelos centrados em preferências domésticas possuem uma série de fraquezas. Por um lado, conseguem explicar as origens domésticas da oposição e do apoio a políticas comerciais (as demandas societárias por proteção ou liberalização), mas atribuem ao governo um papel passivo de tradutor das demandas societárias. Por outro lado, as preferências dos tomadores de decisão podem ajudar a explicar apenas parcialmente o lado da oferta da política comercial, indicando a disposição dos líderes políticos em oferecer proteção ou liberalização. Em suma, os modelos de preferências comerciais parecem fornecer apenas uma explicação inicial sobre a oferta e a demanda por política comercial (Milner, 2002:453).

Assim, pouco se diz sobre o processo pelo qual as demandas de grupos de interesse geram respostas do governo. Grande parte da literatura não buscou identificar as condições mais favoráveis para levar governos a fornecer proteção, rejeitar demandas ou mudar os níveis de pro- 
teção ao longo do tempo (Goldstein, 1986:163; Odell, 1990:141-142; Skidmore e Hudson, 1993:6).

Se, por um lado, eles não propõem nenhuma explicação sobre como as preferências são agregadas em diferentes níveis, por outro, pressupõem que o governo não tenha um papel minimamente independente no processo decisório (Milner, 2002:451; Odell e Willett, 1993:3). Como consequência, dedica-se muita atenção ao "interesse" na proteção e pouca à quantidade e à efetividade da proteção recebida (Goldstein, 1986:163). O que falta nessas explicações são instituições políticas.

\section{Instituições}

Modelos exclusivamente societários - que remontam à tradição do pluralismo político - não explicam como os governos consideram e pesam as diversas demandas societárias por proteção - ou seja, ignoram o lado da oferta da política comercial. Em geral, atribuem um papel passivo aos governos, como meros tradutores das demandas societárias em políticas públicas. Ignoram, em particular, a forma pela qual instituições políticas canalizam e intermedeiam as demandas dos grupos de interesse (Nielson, 2003:470).

Como afirma Odell (1990:153), o comportamento político de indivíduos e grupos responde a oportunidades e a restrições criadas por instituições. O objetivo da análise institucional, portanto, é explicar como as restrições impostas pelas instituições afetam as atividades políticas dos grupos societários (Frieden, 2000:42). Instituições políticas podem influenciar a forma pela qual as preferências dos atores são traduzidas em políticas. Nem todas as preferências têm o mesmo impacto sobre as políticas; as preferências de alguns grupos têm peso maior em qualquer processo decisório. Nesse sentido, instituições criam um viés a favor de certos atores em detrimento de outros; elas podem estabelecer quais grupos domésticos têm mais acesso e voz no processo decisório, além de determinar o grau de permeabilidade do governo a esses interesses. Em outras palavras, elas são responsáveis pelo processo de agregação política das preferências domésticas (Garrett e Lange, 1996:50; Hermann e Hermann, 1989:362; Hudson, 2006:126; Ikenberry, 1988:222-223; Milner, 1997:18; 1998:760-761; 2002:449; Milner e Keohane, 1996:4-6; Nielson, 2003:471-472; Odell e Willett, 1993:3).

Algumas instituições, por exemplo, tendem a conceder aos grupos de interesse acesso privilegiado aos tomadores de decisão e aos instru- 
mentos de política, tornando suas demandas mais difíceis de resistir. Por outro lado, outros tipos de instituição tendem a insular os tomadores de decisão das demandas societárias, conferindo-lhes grande margem de autonomia na formulação e na execução das políticas públicas. Pode-se conceber dois extremos em termos de contexto institucional doméstico: de um lado, as formulações que atribuem ao governo o papel completamente passivo de mero receptor e tradutor de demandas societárias organizadas; de outro, formulações que atribuem ao governo autonomia irrestrita em face das pressões societárias, de modo que são capazes de formular e executar políticas inteiramente alinhadas às preferências dos indivíduos que ocupam os postos de decisão. Entre esses dois extremos, existe uma série de combinações possíveis de elementos institucionais que garantem mais ou menos autonomia aos decisores governamentais e mais ou menos poder às demandas societárias organizadas.

Portanto, embora as preferências domésticas possuam um papel importante na explicação da política comercial, o argumento principal é o de que as instituições políticas agregam essas preferências, concedendo a alguns setores acesso diferenciado às principais instâncias do processo decisório. Dessa forma, é necessário entender as instituições para explicar a oferta de proteção, e não apenas sua demanda; diferentes instituições agregam preferências de forma distinta e, portanto, resultam em políticas diversas. Nesta discussão, são enfatizados os elementos institucionais - identificados na literatura - que tornam os governos mais ou menos permeáveis às demandas societárias. O foco, portanto, recai sobre o insulamento ou a permeabilidade do processo decisório em política econômica externa às demandas dos atores societários.

Três abordagens institucionais principais serão discutidas. Primeiro, uma literatura de influência crescente que se define, sobretudo, pelo método. Batizada de "institucionalismo racional" por Milner (1998), essa abordagem se insere na tradição da escolha racional da ciência política e utiliza amplamente métodos quantitativos para medir e avaliar o impacto de variáveis institucionais sobre os resultados de políticas públicas. Seu foco é sobre o impacto das regras e normas que estruturam o ambiente de interação estratégica dos atores e moldam a forma pela qual resultados coletivos são alcançados. A segunda abordagem, por seu turno, concebe o Estado como uma estrutura organizacional ou um conjunto de leis e arranjos institucionais historicamente contingen- 
tes. Essa abordagem está diretamente associada aos trabalhos de Goldstein $(1986 ; 1988)$. Seu foco é sobre a forma como ideias se tornam institucionalizadas em normas e regras e adquirem persistência ao longo do tempo, garantindo sua influência sobre as políticas. A terceira abordagem, conhecida como abordagem estatal, concebe o Estado como um ator autônomo e independente no processo político. Sua ênfase principal é sobre o comportamento de líderes políticos e executivos do Estado, que são considerados racionais em certa medida, pois respondem a restrições internas e externas na busca de promover políticas que estejam de acordo com suas próprias preferências (Ikenberry, Lake e Mastanduno, 1988:10).

\section{Institucionalismo Racional}

O institucionalismo racional enfoca o impacto das regras e normas que estruturam o ambiente de interação estratégica dos atores e moldam a forma pela qual resultados coletivos são alcançados (Milner, 1998:762). A política externa, nesses estudos, é resultado da agregação de preferências domésticas no contexto de instituições políticas, e o resultado coletivo depende das interações estratégicas desses grupos (idem, ibidem:779).

A literatura pertencente ao subcampo do institucionalismo racional é vasta e investiga o impacto de uma série de variáveis sobre o processo decisório e sobre os resultados de políticas públicas. Em geral, enxerga as instituições como arenas de conflito e cooperação que enviesam resultados a favor de certos grupos (ibidem:762). Ademais, algumas instituições formais dos sistemas políticos nacionais podem torná-los mais ou menos insulados das pressões societárias. Entre as variáveis estudadas, incluem-se o tipo de regime - se democrático ou autoritário, se presidencialista ou parlamentarista -, as regras eleitorais, o tipo de sistema partidário, o tipo de federalismo, o número de pontos de veto etc. Em suma, elementos que definem a natureza do sistema político nacional são variáveis que afetam a forma como as instituições políticas filtram e traduzem as preferências societárias em políticas públicas (Garrett e Lange, 1996; Hudson, 2006:126; Milner, 2002:452-454; Milner e Keohane, 1996:5-6; Nielson, 2003; Thies e Porche, 2007:175; Tsebelis, 1995).

A permeabilidade dos governos a mudanças nas preferências domésticas varia significativamente de acordo com o tipo de regime (Garrett e 
Lange, 1996; Milner e Kubota, 2005). Segundo Garrett e Lange (1996:61), espera-se que a política econômica externa se aproxime daquela prevista por abordagens societárias mais em regimes democráticos do que em autoritários. Ademais, sistemas eleitorais democráticos sempre aproximarão as políticas aos interesses de setores menos produtivos em decorrência do princípio "uma pessoa, um voto" (ibidem:65). A magnitude desse viés varia de acordo com as regras eleitorais, mas eleições democráticas sempre darão maior poder aos setores de bens não comercializáveis do que preveriam os modelos do pluralismo político.

A permeabilidade a mudanças nas preferências societárias é inversamente proporcional ao número de pontos de veto no sistema político isto é, o número de atores institucionais cuja aquiescência é necessária para realizar uma mudança de política (Tsebelis, 1995). Ademais, essas perspectivas, em geral, sugerem que sistemas políticos fragmentados são similares àqueles que possuem muitos pontos de veto e, como eles, são resistentes a mudanças (Milner, 2002:454; Tsebelis, 1995).

Por sua vez, Milner (1997:18) se concentra nas instituições políticas que estabelecem a distribuição dos poderes legislativos entre os atores políticos. No processo decisório, quatro elementos são essenciais como recurso de poder para os atores domésticos: a capacidade de estabelecer a agenda, de emendar as políticas propostas, de ratificar ou vetar propostas e de propor referendos. A forma como o poder é compartilhado afeta as preferências que prevalecerão na tomada de decisão. Quanto maior o controle de um ator político sobre o processo legislativo, maior sua capacidade de implementar políticas que reflitam suas preferências (ibidem:101). Por isso, a relação institucional entre o executivo e o legislativo nas democracias é de suma importância para o entendimento da política econômica externa (ibidem:99; Milner e Rosendorff, 1997).

Nielson (2003) argumenta que presidentes fortes com poderes legislativos significativos e líderes partidários fortes podem ajudar a superar vieses protecionistas na política doméstica. Os resultados empíricos por ele alcançados sugerem que a delegação da competência pela política comercial para presidentes demonstra correlação significativa com a liberalização comercial. Segundo Nielson (ibidem:470-471), reformas comerciais são mais prováveis quando poderes significativos são delegados a líderes partidários do Legislativo ou ao Executivo, vis- 
to que seus mandatos e posições institucionais os levam a considerar mais seriamente a busca de bens públicos. Lima e Santos (2001:121) argumentam na mesma linha: para esses autores, a política externa e, especialmente, a de comércio exterior são comumente delegadas ao Executivo, porque, entre outras razões, "a solução de delegar [...] surge como um freio aos excessos distributivistas de corporações e localidades". Por isso, tenderiam a predominar desenhos institucionais que "assegurem uma autoridade executiva forte" (ibidem:125).

A validade do argumento, no entanto, depende de uma condição importante: os líderes do Poder Executivo em questão devem acreditar nas virtudes do livre-comércio. Nesse caso, as instituições fornecem apenas condições mais propícias à liberalização, mas não a determinam; as ideias e crenças dos políticos são uma variável anterior (Geddes, 1990:218). Dessa forma, Milner (2002:453) conclui não ser pacífico que um maior insulamento dos decisores sempre produzirá políticas liberalizantes. As preferências desses tomadores de decisão também serão determinantes no resultado.

Como argumenta Milner (1997:19), a conclusão geral dessa literatura é que as instituições são importantes como fator explicativo, mas as preferências são primordiais, uma vez que delimitam o grau de variação nos resultados que as instituições podem produzir.

\section{Ideias e Instituições}

A segunda abordagem institucional a ser discutida concebe o Estado como uma estrutura organizacional ou um conjunto de leis e arranjos institucionais historicamente contingentes. Nesse sentido, a política comercial pode ser entendida como um conjunto de regras de decisão que refletem as ideias e os vieses dos tomadores de decisão que as criaram. Essa abordagem está associada sobretudo aos trabalhos de Goldstein $(1986 ; 1988)$. Seu foco é sobre a forma pela qual ideias se tornam institucionalizadas em normas e regras e adquirem persistência ao longo do tempo, garantindo sua influência sobre as políticas. A explicação da política comercial, nesse caso, passa pela inter-relação entre duas variáveis: as ideias dos tomadores de decisão e as instituições políticas. As ideias são importantes na medida em que se institucionalizam em regras e normas que restringem o comportamento de indivíduos e grupos de dentro e de fora do Estado (Goldstein, 1988:214; Goldstein e Keohane, 1993:12; Sikkink, 1991:2 e 25). 
A partir do momento em que as ideias influenciam o desenho organizacional das agências do Estado, sua influência vai se refletir nos incentivos para aqueles que estão dentro e fora da organização. Esse mecanismo causal enfatiza a forma como instituições políticas, na forma de agências, leis, normas e procedimentos, medeiam a relação entre ideias e políticas públicas, especialmente a política externa (Goldstein, 1988:181; Goldstein e Keohane, 1993:20). Isso também explica por que algumas práticas e instituições sobrevivem ao tempo mesmo que as ideias que lhes deram origem já não sejam dominantes na arena política (Goldstein, 1988:181).

São de interesse particular as regras que regulam a relação entre governo e setor privado nas questões de política comercial, especialmente aquelas que balizam a avaliação do Estado sobre a legitimidade das demandas feitas pelos atores societários (idem, 1986:161; 1988:180; Ikenberry, 1988:228). Goldstein (1986; 1988) identifica três dessas regras para o caso da política comercial norte-americana. Primeiro, a transferência da responsabilidade institucional pela política comercial do Legislativo para o Executivo, a qual implicou que interesses particularistas não pudessem mais dominar as questões comerciais. Segundo, o processo decisório em política comercial caracteriza-se por normas, valores e instituições que protegem o mercado americano de práticas predatórias de produtores estrangeiros. Terceiro, por questões de legitimidade, o governo norte-americano precisa parecer responsável perante cidadãos e grupos domésticos; entretanto, isso não significa dar a eles o que eles querem. Então, a regra estipula que, se tiver de ser oferecida, a proteção deve ser simbólica e o mais irrestrita possível, ou seja, com menos custos políticos (Goldstein, 1986:166).

Thies e Porche (2007) obtiveram resultados empíricos que sustentam o argumento de Goldstein. Conforme concluem em seu estudo de caso, as instituições da política comercial norte-americana foram desenhadas para aparentar a concessão de proteção, sem fazê-lo de forma substantiva.

A abordagem de Goldstein trabalha implicitamente com a noção de que, uma vez inseridas em instituições, as ideias influenciarão automaticamente a formulação e a execução da política econômica externa. Segundo Drezner (2000), no entanto, a explicação de como as ideias inseridas em instituições persistem e influenciam a política externa é incompleta. Uma abordagem de política burocrática, por sua vez, permi- 
tiria enfocar as estratégias que essas instituições deveriam adotar para sobreviver e alcançar sucesso na arena política, na qual elas concorrem com outras instituições (ibidem:733).

Para Drezner, instituições enfrentam um trade-off entre sobrevivência e sucesso (em termos de influência sobre resultados). Agências insuladas de outras burocracias têm maior chance de sobrevivência (isto é, de não serem absorvidas por outras burocracias), mas dificilmente conseguirão influenciar os grandes contornos das políticas. Por outro lado, agências inseridas em contextos burocráticos mais amplos têm menos chances de manter suas ideias originárias intactas, mas, se sobreviverem, têm mais chances de traduzir suas ideias em políticas efetivas. Em suma, o posicionamento das instituições em relação às outras instituições existentes influencia sua capacidade de sobreviver e de interferir nos resultados (ibidem:746).

\section{Autonomia e Capacidade Estatal}

A terceira abordagem, conhecida como abordagem estatal, concebe o Estado como um ator autônomo e independente no processo político, cujas iniciativas próprias são centrais. Sua ênfase principal é sobre o comportamento de líderes políticos e executivos do Estado (elite burocrática), que são considerados racionais em certa medida, pois buscam promover políticas que estejam de acordo com suas próprias preferências, em ambientes de restrições internas e externas (Ikenberry, 1988:220; Ikenberry, Lake e Mastanduno, 1988:10). Como aponta Geddes (1990:217), ações de governo podem promover as preferências autônomas de membros da elite burocrática. Por vezes, líderes governamentais implementam mudanças em políticas sem levar em consideração demandas de importantes grupos políticos e econômicos (ibidem). Essa abordagem se concentra, portanto, na estrutura institucional do Estado e na capacidade dos atores políticos e administrativos, que ocupam posições nessa estrutura, de formular e implementar a política econômica externa (Evans, Rueschemeyer e Skocpol, 1985; Ikenberry, Lake e Mastanduno, 1988:1-2).

O que caracteriza a abordagem é sobretudo o conceito de autonomia estatal $^{4}$. Geddes (1990:217) a define como a capacidade dos agentes governamentais de formular e de executar políticas de forma independente. Ademais, autonomia estatal implica que os agentes governamentais (1) possuem preferências que não são meros reflexos das pre- 
ferências de grupos societários importantes e (2) têm capacidade, em termos organizacionais, coercitivos e de expertise, de implementar as decisões baseadas em suas próprias preferências (ibidem). Garrett e Lange (1996:67) afirmam que existe autonomia burocrática quando (1) um grau considerável de autoridade é delegado à burocracia e (2) as preferências dos burocratas são distintas daquelas dos políticos eleitos. Por sua vez, Müller e Risse-Kappen (1993:34) definem autonomia estatal como a situação em que tomadores de decisão em política externa são relativamente independentes de demandas e de pressões societárias.

As abordagens estatais fazem um contraponto direto às societárias. Para estas, explicações da política econômica externa se baseiam na disputa entre grupos de interesse domésticos; atores governamentais e instituições não possuem papel autônomo nem interveniente na formação das políticas. Como afirma Goldstein (1988:184), poucos tentam explicar o conteúdo das políticas como resultado dos interesses e das crenças do Estado. Pelo contrário, em geral, não se leva em consideração a ação independente do Estado. Entretanto, na realidade, atores governamentais, em especial agências burocráticas, exercem uma influência importante sobre a política que não é captada por modelos baseados apenas nas demandas societárias. Thacker (2000:37) assevera que o Estado por si próprio é um ator-chave no processo de mudança das políticas; por isso, não se deve enxergá-lo como simples receptor de pressões internacionais e societárias. Isso implica que os atores governamentais nem sempre mudam sua maneira de formular e de implementar políticas de acordo com as preferências dos atores societários (Garrett e Lange, 1996:67; Ikenberry, Lake e Mastanduno, 1988:7; Sikkink, 1991:10; Thacker, 2000:44). Como argumentam Garrett e Lange (1996:54), quanto maior o grau de autoridade delegado a agências burocráticas independentes, menor o papel das preferências privadas nos processos de mudança das políticas.

O que todas as abordagens estatais possuem em comum é a atenção às formas institucionais do Estado e às relações deste com a sociedade. No entanto, cada autor utiliza critérios específicos e atribui conteúdo distinto às variações possíveis no grau de autonomia estatal/burocrática de cada país.

Katzenstein (1977a; 1977b) sugere uma diferenciação dos países em termos de: estrutura do sistema político e de seu grau de centralização; 
nível de fragmentação e de polarização societárias; e redes de políticas (policy networks), isto é, a estrutura que liga o sistema político à sociedade e a medida em que esta é controlada pelo Estado, pela sociedade ou se é corporativista. Esses três elementos compõem a estrutura doméstica dos países (Katzenstein, 1977a:596). O conceito de estrutura doméstica guarda grande semelhança com o de sistemas nacionais de economia política de Gilpin (2001:149), os quais são definidos pelo papel do Estado na economia, pela estrutura do setor privado (grau de concentração, coordenação etc.) e pelos diferentes padrões de inter-relação entre Estado e setor privado.

Essa abordagem sugere que os países diferem na medida em que seus governos e sociedades são centralizados e no leque de instrumentos de política disponíveis para os executivos do Estado na condução da política econômica externa. Eles também diferem no grau de autonomia que os atores governamentais possuem em relação às forças societárias, visto que as estruturas domésticas determinam a seletividade do sistema político em relação às demandas societárias.

A autonomia estatal é definida por Katzenstein (1976) em termos da força ou da fraqueza do Estado em sua relação com a sociedade; assim, a forma como os países responderiam a pressões econômicas externas dependeria da força das instituições políticas. Estados fracos são dominados pelos atores societários; suas decisões de política econômica externa são restringidas pela opinião pública, grupos de interesse, parlamento e demais atores externos ao Poder Executivo. Por outro lado, Estados fortes são capazes de insular os tomadores de decisão de pressões políticas imediatistas.

Cortell e Davis Jr. (1996:454) definem a estrutura doméstica como a organização da autoridade sobre a tomada de decisão e o padrão de relações Estado-sociedade. A organização do processo decisório varia de acordo com a centralização ou a descentralização, dependendo do número de agências burocráticas e de ministérios que possuem competência sobre determinada questão. O padrão de relações Estado-sociedade diz respeito aos arranjos institucionais que conferem aos atores societários acesso à formulação e à implementação de políticas. Os autores tratam as relações Estado-sociedade em termos de proximidade e distância (e não de força ou fraqueza). As relações são distantes quando atores societários são excluídos do processo de formulação de políticas. Por outro lado, são próximas quando as instituições do processo 
decisório incorporam atores societários ou seus interesses (ibidem:454-455).

Geddes (1990:217) e Sikkink (1991:11 e 22) chamam a atenção para questões relativas à capacidade institucional do Estado, isto é, para os meios e instrumentos de que o Estado dispõe para implementar suas preferências ). Capacidade estatal diz respeito aos instrumentos administrativos e coercitivos disponíveis ao poder público para implementar os objetivos do governo. Como define Sikkink, "capacidade estatal é um conceito relacional: um Estado é considerado forte ou capaz em relação às tarefas e objetivos que lhe são conferidos" (1991:11; tradução do autor).

A capacidade estatal se define pela natureza das estruturas organizacionais do Estado, as normas e procedimentos que governam a burocracia, e sua capacidade técnica. Depende, portanto, de características do governo e da administração pública, tais como carreiras relativamente insuladas dos interesses socioeconômicos e políticos dominantes; procedimentos meritocráticos de recrutamento, remuneração, treinamento, promoção e demissão que concentrem expertise e recursos humanos de alta qualidade na burocracia e reduzam a influência partidária sobre as ações e as decisões relativas à organização interna do Estado; a existência de instrumentos econômicos por meio dos quais os atores governamentais possam manipular os incentivos para os atores privados; e limitações na participação política que tornem possível que os atores governamentais ignorem as preferências de alguns grupos societários sem precisar temer as consequências eleitorais (Geddes, 1990:218; Sikkink, 1991:172-173 e 189).

Por fim, Evans (1995) propõe uma solução conceitual para os dilemas da relação entre autonomia estatal e preferências societárias - ou entre insulamento e captura. Seu conceito de autonomia inserida (embedded autonomy) integra os dois elementos centrais nas discussões de autonomia estatal: a organização interna do Estado e as relações Estado-sociedade. A autonomia inserida combina insulamento burocrático com intensa relação com a estrutura social (ibidem:50). A inserção é necessária para a obtenção das informações e dos recursos necessários para a implementação das políticas (ibidem:58; Geddes, 1990:220).

É preciso notar que autonomia e inserção podem produzir resultados indesejáveis se não existirem conjuntamente. Na ausência de autonomia, desaparece a distinção entre inserção e mera captura por grupos 
de interesse. Por outro lado, agências insuladas podem formar coalizões e estabelecer relações cooperativas com atores societários, mas não são dominadas por eles (Evans, 1995:59; Geddes, 1990:220).

Em suma, a literatura relativa às questões de autonomia estatal indica que as possíveis variações na estrutura organizacional do Estado e em suas relações com a sociedade - e as diferentes combinações entre as duas variáveis - criam diferentes resultados de políticas públicas. Primeiro, criam graus distintos de permeabilidade do processo decisório a atores societários; segundo, criam diferentes graus de capacidade estatal, ou seja, de propensão a que as políticas reflitam as preferências dos atores governamentais. Essa literatura não permite previsões precisas sobre quais são os resultados mais prováveis dado determinado contexto institucional, mas fornece orientações interessantes sobre as perguntas que devem ser feitas e as variáveis que devem ser investigadas ao se analisar os determinantes domésticos da política econômica externa.

\section{Mudança Institucional}

É ainda pouco explorado o campo da mudança institucional. As abordagens institucionais aqui discutidas utilizam instituições como variáveis independentes ou intervenientes em suas explicações. No entanto, também se pode estudá-las como variáveis dependentes; em termos metodológicos, isso significa endogeneizar as instituições nos modelos explicativos. Ainda são relativamente limitadas as explicações sobre as variáveis que influenciam as mudanças institucionais.

Como apontam Frieden (2000:41) e Garrett e Lange (1996), instituições podem ser analisadas de duas formas: estaticamente (isto é, instituições são constantes, não variam no modelo) ou endogenamente (isto é, busca-se explicar o que causa mudanças institucionais). Os teóricos do institucionalismo racional são os que mais avançaram nessa empreitada. Sua premissa fundamental é que os atores avaliam se as instituições existentes são de seu interesse. Se os custos de observância às instituições existentes forem altos, eles podem cogitar mudar as instituições em uma direção que lhes seja favorável (Frieden, 2000:41-42; Ikenberry, 1988:224). Entretanto, não me deterei sobre esse aspecto das explicações institucionais, dado que o foco da investigação privilegia o estudo das instituições em seu papel de intermediárias entre preferências individuais e políticas públicas. 


\section{Limitações das Abordagens Institucionais}

Como reconhece Ikenberry (1988:242), a abordagem institucional oferece apenas algumas das respostas necessárias para a explicação da política externa econômica. A abordagem privilegia os constrangimentos estruturais com que se deparam atores societários e governamentais no processo de tomada de decisão. Explicações centradas em restrições e em constrangimentos, porém, indicam quais cursos de ação não são possíveis ou factíveis, mas dizem pouco sobre os que são (ibidem). Em último caso, o leque de resultados possíveis é determinado pela estrutura doméstica de preferências, podendo as instituições apenas explicar variações dentro desse leque.

Faltam às abordagens institucionais elementos explicativos relacionados à "agência" dos indivíduos que operam no âmbito das instituições. Mais especificamente, faltam explicações das motivações e das capacidades dos indivíduos para agir politicamente em um dado contexto institucional de restrições e de oportunidades. Esses elementos devem ser buscados nos modelos que privilegiam as preferências individuais (sejam de atores societários ou governamentais) e naqueles que investigam os fatores ideacionais e cognitivos do comportamento humano, associados aos modelos de ação coletiva que atentam para os custos e para as oportunidades da ação política. Ademais, a necessidade de se incluir as ideias dos tomadores de decisão como elemento explicativo será ainda mais premente quanto maior for a autonomia estatal no caso estudado. É justamente nos casos em que atores governamentais possuem maior margem de atuação que suas ideias e preferências serão mais importantes na formação das políticas públicas.

Cabe destacar ainda que o campo da análise institucional em política econômica externa apresenta escassos resultados empíricos. Na vertente do institucionalismo racional, pode-se encontrar análises estatísticas feitas com base em amplas bases de dados. No entanto, variáveis institucionais são de difícil mensuração e operacionalização estatística, o que confere uma grande margem de arbitrariedade às análises e prejudica a possibilidade de generalização dos resultados. Por outro lado, as outras duas vertentes mais interpretativas também oferecem poucos estudos de casos detalhados e, menos ainda, análises comparativas entre diversos países em termos de suas estruturas institucionais. O avanço do campo, portanto, depende de um esforço maior de confrontação dos modelos teóricos e interpretativos com a realidade. 


\section{CONCLUSÃO}

Teorias e modelos explicativos da política econômica externa devem integrar quatro elementos principais discutidos neste capítulo: (a) a origem das preferências dos atores societários; (b) a forma como elas são agregadas por instituições socioeconômicas em demandas por políticas organizadas; (c) a origem das preferências dos atores governamentais; e (d) o papel das instituições políticas na filtragem e na canalização de algumas preferências em detrimento de outras. Entretanto, nenhum dos modelos apresentados satisfaz a todos esses quesitos isoladamente. Como sugere Milner (1999:104), há um consenso crescente de que preferências e instituições são importantes e mutuamente determinadas, mas resta muito a fazer em termos de modelagem teórica e de investigação empírica.

Os modelos teóricos sobre a formação de preferências individuais e sobre a ação coletiva em torno de bens públicos são bem desenvolvidos e formalizados, além de contarem com vasta produção empírica. Contudo, fornecem apenas explicações parciais.

As abordagens institucionais ainda têm um caminho a percorrer na definição precisa de conceitos e de variáveis que sejam aceitos consensualmente. Há ainda muita divergência sobre quais são as variáveis institucionais centrais e os níveis de agregação mais relevantes. Os estudos institucionais padecem também da falta de acúmulo empírico, talvez pelas dificuldades de mensuração e instrumentalização das variáveis; faltam sobretudo estudos de caso e estudos comparados detalhados que deem conta dos efeitos das variações institucionais - às vezes sutis - em diferentes países.

Entre as abordagens teóricas examinadas, as que buscam explicar resultados de políticas por meio de ideias e crenças são as menos desenvolvidas. Certamente, a natureza imaterial do objeto o torna menos suscetível à modelagem teórica. Não obstante, ideias e crenças são centrais na formação das preferências de atores governamentais. É preciso uma compreensão mais apurada de como esses atores formam suas preferências.

Portanto, uma explicação consistente da formação e da execução da política econômica externa, em especial da política externa comercial, deve ser capaz de integrar os modelos parciais existentes de forma coe- 
rente. São necessárias teorias que levem em conta tanto as preferências dos atores domésticos quanto as instituições políticas domésticas.

(Recebido para publicação em abril de 2009) (Aprovado para publicação em julho de 2009)

\section{NOTAS}

1. Para uma discussão mais completa dos diferentes tipos de atores domésticos relevantes para o estudo da política externa, ver Hudson (2006:125-141).

2. Uma versão embrionária desse argumento pode ser encontrada em Hoekman (1989:714).

3. Para uma revisão mais abrangente da literatura sobre o impacto das ideias nas políticas públicas, ver Faria (2003).

4. É importante fazer a ressalva de que o termo autonomia estatal é impreciso e pode causar confusão. Em praticamente toda a literatura, ele é utilizado como sinônimo de autonomia burocrática, termo esse que seria mais apropriado, tendo em vista que os estudos dessa vertente se concentram no papel do Poder Executivo, mais especificamente nas elites burocráticas dos órgãos e das agências governamentais que lhe dão suporte.

\section{REFERÊNCIAS BIBLIOGRÁFICAS}

ALLISON, Graham T. e HALPERIN, Morton H. (1972), “Bureaucratic Politics: A Paradigm and Some Policy Implications". World Politics, vol. 24, pp. 40-79.

ALT, James et alii. (1996), “The Political Economy of International Trade: Enduring Puzzles and an Agenda for Inquiry". Comparative Political Studies, vol. 29, no 6, pp. 689-717.

ALT, James et alii. (1999), "Asset Specificity and the Political Behavior of Firms: Lobbying for Subsidies in Norway". International Organization, vol. 53, no 1, pp. 99-116.

BALDWIN, Robert E. (1989), “The Political Economy of Trade Policy". The Journal of Economic Perspectives, vol. 3, no 4, pp. 119-135.

BHAGWATI, Jagdish. (1988), Protectionism. Cambridge, The MIT Press.

CAPORASO, James A. e LEVINE, David P. (1992), Theories of Political Economy. Cambridge, Cambridge University Press. 


\section{Raphael Coutinho da Cunha}

CORTELL, Andrew P. e DAVIS JR., James W. (1996), “How Do International Institutions Matter? The Domestic Impact of International Rules and Norms". International Studies Quarterly, vol. 40, no 4, pp. 451-478.

DAVIS, Christina L. (2003), Food Fights over Free Trade: How International Institutions Promote Agricultural Trade Liberalization. Princeton/Oxford, Princeton University Press.

. (2004), "International Institutions and Issue Linkage: Building Support for Agricultural Trade Liberalization". American Political Science Review, vol. 98, no 1, pp. 153-169.

DOWNS, Anthony. (1999), Uma Teoria Econômica da Democracia. São Paulo, Edusp.

DREZNER, Daniel W. (2000), "Ideas, Bureaucratic Politics, and the Crafting of Foreign Policy". American Journal of Political Science, vol. 44, no 4, pp. 733-749.

EVANS, Peter B. (1995), Embedded Autonomy: States and Industrial Transformation. Princeton, Princeton University Press.

, RUESCHEMEYER, Dietrich e SKOCPOL, Theda. (1985), Bringing the State Back In. Cambridge, Cambridge University Press.

FARIA, Carlos Aurélio Pimenta de. (2003), “Idéias, Conhecimento e Políticas Públicas: Um Inventário Sucinto das Principais Vertentes Analíticas Recentes". Revista Brasileira de Ciências Sociais, vol. 18, no 51, pp. 21-30.

FRIEDEN, Jeffry. (2000), "The Method of Analysis: Modern Political Economy", in J. Frieden, M. Pastor Jr. e M. Tomz (eds.), Modern Political Economy and Latin America: Theory and Policy. Boulder, Westview Press.

e ROGOWSKI, Ronald. (1996), “The Impact of the International Economy on National Policies: An Analytical Overview", in H. V. Milner e R. O. Keohane (eds.), Internationalization and Domestic Politics. Cambridge, Cambridge University Press, pp. 25-47.

GARRETT, Geoffrey e LANGE, Peter. (1996), “Internationalization, Institutions and Political Change", in H. V. Milner e R. O. Keohane (eds.), Internationalization and Domestic Politics. Cambridge, Cambridge University Press, pp. 48-75.

GEDDES, Barbara. (1990), “Building 'State' Autonomy in Brazil, 1930-1964". Comparative Politics, vol. 22, no 2, pp. 217-235.

GILPIN, Robert. (2001), Global Political Economy: Understanding the International Economic Order. Princeton, Princeton University Press.

GOLDSTEIN, Judith. (1986), “The Political Economy of Trade: Institutions of Protection". The American Political Science Review, vol. 80, no 1, pp. 161-184.

. (1988), "Ideas, Institutions, and American Trade Policy". International Organization, vol. 42, no 1, pp. 179-217.

e KEOHANE, Robert O. (1993), “Ideas and Foreign Policy: An Analytical Framework", in J. Goldstein e R. O. Keohane (eds.), Ideas and Foreign Policy: Beliefs, Institutions, and Political Change. Ithaca, Cornell University Press, pp. 3-30.

GOLDSTEIN, Judith e MARTIN, Lisa L. (2000), “Legalization, Trade Liberalization, and Domestic Politics: A Cautionary Note". International Organization, vol. 54, no 3, pp. 603-632. 


\section{Preferências Domésticas e Instituições do Processo Decisório...}

HATHAWAY, Oona A. (1998), "Positive Feedback: The Impact of Trade Liberalization on Industry Demands for Protection". International Organization, vol. 52, no 3, pp. 575-612.

HERMANN, Margaret G. e HERMANN, Charles F. (1989), “Who Makes Foreign Policy Decisions and How: An Empirical Inquiry". International Studies Quarterly, vol. 33, no 4, pp. 361-387.

HOEKMAN, Bernard M. (1989), “Determining the Need for Issue Linkages in Multilateral Trade Negotiations". International Organization, vol. 43, no 4, pp. 693-714.

HOLLIS, Martin e SMITH, Steve. (1986), "Roles and Reasons in Foreign Policy Decision Making". British Journal of Political Science, vol. 16, no 3, pp. 269-286.

HUDSON, Valerie M. (2006), Foreign Policy Analysis: Classic and Contemporary Theory. Lanham, Rowman \& Littlefield Publishers.

IKENBERRY, G. John. (1988), “Conclusion: An Institutional Approach to American Foreign Economic Policy”. International Organization, vol. 42, no 1, pp. 219-243.

, LAKE, David A. e MASTANDUNO, Michael. (1988), "Introduction: Approaches to Explaining American Foreign Economic Policy". International Organization, vol. 42, no 1, pp. 1-14.

KATZENSTEIN, Peter J. (1976), “International Relations and Domestic Structures: Foreign Economic Policies of Advanced Industrial States". International Organization, vol. 30, no 1 , pp. 1-45.

. (1977a), "Introduction: Domestic and International Forces and Strategies of Foreign Economic Policy”. International Organization, vol. 31, no 4, pp. 587-606.

. (1977b), “Conclusion: Domestic Structures and Strategies of Foreign Economic Policy”. International Organization, vol. 31, no 4, pp. 879-920.

KEMP, Simon. (2007), "Psychology and Opposition to Free Trade". World Trade Review, vol. 6 , no 1 , pp. 25-44.

KRUGMAN, Paul R. (1983), “New Theories of Trade among Industrial Countries". The American Economic Review, vol. 73, no 2, pp. 343-347.

e OBSTFELD, Maurice. (2001), Economia Internacional: Teoria e Política (5 a ed.). São Paulo, Pearson Education do Brasil.

LIMA, Maria Regina Soares de e SANTOS, Fabiano. (2001), “O Congresso e a Política de Comércio Exterior". Lua Nova, no 52, pp. 121-149.

LUSZTIG, Michael. (2004), The Limits of Protectionism: Building Coalitions for Free Trade. Pittsburgh, University of Pittsburgh Press.

MILNER, Helen V. (1988), Resisting Protectionism. Princeton, Princeton University Press. . (1997), Interests, Institutions, and Information. Princeton, Princeton University Press.

. (1998), "Rationalizing Politics: The Emerging Synthesis of International, American, and Comparative Politics". International Organization, vol. 52, no 4, pp. 759-786.

. (1999), "The Political Economy of International Trade". Annual Review of Political Science, no 2, pp. 91-114. 


\section{Raphael Coutinho da Cunha}

__. (2002), "International Trade”, in W. Carlsnaes, T. Risse e B. A. Simmons (eds.), Handbook of International Relations. London, Sage Publications, pp. 448-461.

e KEOHANE, Robert O. (1996), "Internationalization and Domestic Politics: An Introduction", in H. V. Milner e R. O. Keohane (eds.), Internationalization and Domestic Politics. Cambridge, Cambridge University Press, pp. 3-24.

MILNER, Helen V. e KUBOTA, Keiko. (2005), “Why the Move to Free Trade? Democracy and Trade Policy in the Developing Countries". International Organization, vol. 59, no 1, pp. 107-143.

MILNER, Helen e ROSENDORFF, Peter. (1997), “Democratic Politics and International Trade Negotiations: Elections and Divided Governments as Constraints on Trade Liberalization". The Journal of Conflict Resolution, vol. 41, no 1, pp. 117-146.

MILNER, Helen e YOFFIE, David B. (1989), "Between Free Trade and Protectionism: Strategic Trade Policy and a Theory of Corporate Trade Demands". International Organization, vol. 43, no 2, pp. 239-272.

MORAVCSIK, Andrew. (1997), “Taking Preferences Seriously: A Liberal Theory of International Politics". International Organization, vol. 51, no 4, pp. 513-553.

MÜLLER, Harald e RISSE-KAPPEN, Thomas. (1993), "From the Outside In and from the Inside Out: International Relations, Domestic Politics, and Foreign Policy", in D. Skidmore e V. M. Hudson (eds.), The Limits of State Autonomy: Societal Groups and Foreign Policy Formulation. Boulder, Westview Press, pp. 25-48.

NIELSON, Daniel L. (2003), "Supplying Trade Reform: Political Institutions and Liberalization in Middel-income Presidential Democracies". American Journal of Political Science, vol. 47, no 3, pp. 470-491.

ODELL, John S. (1990), “Understanding International Trade Policies: An Emerging Synthesis". World Politics, vol. 43, no 1, pp. 139-167.

e WILLETT, Thomas D. (1993), "Gains From Exchange: An Introduction”, in J. S. Odell e T. D. Willett (eds.), International Trade Policies: Gains from Exchange between Economics and Political Science. Ann Arbor, University of Michigan Press, pp. 1-19.

OLSON, Mancur. (1977), The Logic of Collective Action: Public Goods and the Theory of Groups. Cambridge, Harvard University Press.

PUTNAM, Robert D. (1988), “Diplomacy and Domestic Politics: The Logic of Two-Level Games". International Organization, vol. 42, no 3, pp. 427-460.

RODRIK, Dani. (1994), "What Does the Political Economy Literature on Trade Policy (Not) Tell Us That We Ought to Know?". NBER Working Paper Series, no 4.870.

e MAYDA, Anna Maria. (2001), “Why Are Some People (and Countries) More Protectionist Than Others?". NBER Working Paper Series, no 8.461.

ROGOWSKI, Ronald. (1987), "Political Cleavages and Changing Exposure to Trade". The American Political Science Review, vol. 81, no 4, pp. 1121-1137.

SCHEVE, Kenneth F. e SLAUGHTER, Matthew J. (2001), “What Determines Individual Trade-Policy Preferences?". Journal of International Economics, vol. 54, pp. 267-292.

SIKKINK, Kathryn. (1991), Ideas and Institutions: Developmentalism in Brazil and Argentina. Ithaca, Cornell University Press. 
SKIDMORE, David e HUDSON, Valerie M. (1993), “Establishing the Limits of State Autonomy: Contending Approaches to the Study of State-Society Relations and Foreign Policy-Making", in D. Skidmore e V. M. Hudson (eds.), The Limits of State Autonomy: Societal Groups and Foreign Policy Formulation. Boulder, Westview Press, pp. 1-22.

THACKER, Strom C. (2000), Big Business, the State, and Free Trade: Constructing Coalitions in Mexico. Cambridge, Cambridge University Press.

THIES, Cameron G. e PORCHE, Schuyler. (2007), “Crawfish Tails: A Curious Tale of Foreign Trade Policy Making”. Foreign Policy Analysis, vol. 3, no 2, pp. 171-187.

TSEBELIS, George. (1995), "Decision Making in Political Systems: Veto Players in Presidentialism, Parliamentarism, Multicameralism and Multipartyism". British Journal of Political Science, vol. 25, no 3, pp. 289-325.

VAN BELLE, Douglas. (1993), "Domestic Imperatives and Rational Models of Foreign Policy Decision Making", in D. Skidmore e V. M. Hudson (eds.), The Limits of State Autonomy: Societal Groups and Foreign Policy Formulation. Boulder, Westview Press, pp. 151-183. 


\title{
Raphael Coutinho da Cunha
}

\author{
ABSTRACT \\ Domestic Preferences and Institutions in the Foreign Economic Policy \\ Decision-Making Process
}

This article discusses the dynamics of nongovernmental domestic actors in the foreign economic policy decision-making process. The article addresses four questions: (1) Do nongovernmental actors influence foreign economic policy decisions? (2) What determines their preferences for given policies? (3) What institutional characteristics in the decision-making process offer greater or lesser permeability to demands by domestic actors? (4) Which institutional variables affect the interaction between societal and governmental interests? The author discusses the answers to these questions provided by the literature. The argument is that the existing theoretical perspectives offer only partial explanations to the dynamics at hand and need to be better integrated in order to adequately understand them.

Key words: foreign economic policy; interest groups; institutions

\section{RÉSUMÉ}

Préférences Nationales et Institutions du Processus Décisionnel en Politique Économique Extérieure

Dans cet article, on discute la dynamique de la participation d'acteurs domestiques non-gouvernementaux dans le processus décisionnel de la politique économique extérieure. On examine quatre questions: 1) les acteurs nationaux non-gouvernementaux influent-ils sur les décisions de politique économique extérieure?; 2) qu'est-ce qui fait que ces acteurs préfèrent certaines politiques?; 3) quelles caractéristiques institutionnelles du processus décisionnel offrent une plus grande perméabilité aux demandes des acteurs nationaux?; 4) quelles variables institutionnelles nuisent à l'intéraction d'acteurs de la société et du gouvernement? On discute les réponses que la littérature offre à ces questions. On avance que les perspectives théoriques existantes offrent des explications partielles pour l'objet à l'étude et doivent être intégrées pour qu'il puisse être compris de façon adéquate.

Mots-clé: politique économique extérieure; groupes d'intérêts; institutions 